\title{
Loneliness, Burnout, and Other Types of Emotional Distress Among Family Medicine Physicians: Results From a National Survey
}

\author{
Samuel Ofei-Dodoo, PhD, MPA, MA, Rebecca Mullen, MD, MPH, \\ Andrew Pasternak, MD, MS, Christina M. Hester, PhD, MPH, Elisabeth Callen, PhD, GStat, \\ Edward James Bujold, MD, Jennifer K. Carroll, MD, MPH, and Kim S. Kimminau, PhD
}

Purpose: This study assessed the prevalence of loneliness, burnout, and depressive symptoms from a national sample of family medicine physicians.

Methods: We conducted a cross-sectional survey of 401 physicians who were members of the American Academy of Family Physicians (AAFP) and AAFP National Research Network between December 7, 2019, and January 20, 2020. The study participants completed an anonymous, 30-item survey measuring loneliness, burnout, symptoms of depression, fatigue, in addition to providing demographic information.

Results: The response rates were 16.3\% (401 of 2456) for all the physicians, $7.0 \%$ (113 of 1606) for the AAFP NRN member physicians, and 33.9\% (288 of 850) for the AAFP member insight physicians. The prevalence of loneliness, burnout, and depressive symptoms was 44.9\% (165 of 367), 45.1\% (181 of 401), and 44.3\% (163 of 368) respectively. The physicians who experienced a greater feeling of loneliness compared with those who experienced a lesser feeling of loneliness were more likely to report at least 1 manifestation of burnout (69.1\% vs $27.4 \%, P<.01)$, screen positive for depression $(66.0 \%$ vs $27.6 \%, P<.01)$, and experience a higher degree of fatigue $(59.5 \%$ vs $32.4 \%, P<.01)$. Depressive symptoms (odds ratio $[0 R]=5.08 ; 95 \%$ confidence interval $[\mathrm{CI}], 4.64-7.94 ; P<.001)$, overwhelming exhaustion $(\mathrm{OR}=7.19 ; 95 \% \mathrm{CI}, 4.03$ to 12.02 ; $P<.001)$, and burnout $(\mathrm{OR}=4.61 ; 95 \% \mathrm{CI}, 2.96-7.19 ; P<.001)$ were associated with loneliness status.

Conclusion: Our findings demonstrate that loneliness is common in practicing family medicine physicians and is significantly associated with burnout and depression. Future work is needed to understand the various interactions and relationships among loneliness, burnout, and depression to help inform effective interventions. ( $\mathrm{J}$ Am Board Fam Med 2021;34:531-541.)

Keywords: Burnout, Cross-Sectional Studies, Depression, Family Medicine, Family Physicians, Loneliness, Mental Health, Occupational Burnout, Prevalence, Primary Care, Primary Health Care, Surveys and Questionnaires

\section{Introduction}

Loneliness, defined as the internal perception of inadequate personal relationships, ${ }^{1}$ poses a significant

This article was externally peer reviewed.

Submitted 28 October 2020; revised 16 January 2021; accepted 18 January 2021.

From the Department of Family and Community Medicine, University of Kansas School of Medicine, Wichita, KS (SO-D); Department of Family Medicine, University of Colorado School of Medicine, Boulder (RM, JKC); Silver Sage Center for Family Medicine, Reno School of Medicine, University of Nevada, Reno (AP); American Academy of Family Physicians, Leawood, KS (CMH, EC); Department of Family Medicine, Wake Forest School of Medicine, Wake Forest University, Winston Salem, NC (EJB), Office of the Executive Vice Chancellor for Health Affairs, University of Missouri, Columbia, MO (KSK).

Funding: None.

Conflicts of interest: None.

Corresponding author: Samuel Ofei-Dodoo, PhD, MPA MA, Department of Family and Community Medicine, health concern. Loneliness is associated with a variety of negative physical and mental health conditions, such as hypertension, cardiovascular disease, stroke, depression, suicide, and even death. ${ }^{2-4}$ The prevalence of loneliness has been cited as high as $35 \%$ in US adults above 45 years old. ${ }^{5}$ Given these concerns, leaders in the field have called for loneliness to be deemed a public health priority in the United States. ${ }^{6}$

As a state of emotional discomfort, loneliness likely is related to other conditions of psychological distress such as burnout. Literature supports that over $50 \%$ of physicians experience symptoms of

University of Kansas School of Medicine-Wichita, 1010 N. Kansas, Wichita, KS 67214, Phone. 316-293-1879, Fax: 316293-2696 (E-mail: sofeidodoo@kumc.edu). 
burnout, such as emotional exhaustion, cynicism, and reduced professional efficiency. ${ }^{7-9}$ Burnout among health care providers is associated with increased medical errors, ${ }^{10,11}$ dishonest clinical behaviors, ${ }^{12}$ lower patient satisfaction, ${ }^{13,14}$ and greater job turnover. ${ }^{15}$ Similar to loneliness, burnout has been called a public health crisis in the United States. ${ }^{16}$

While there is literature that contributes to our understanding of burnout in health care providers, less is known about loneliness experienced by physicians and the relationship between loneliness and burnout. Loneliness is thought to be prevalent among physicians, with a Harvard Business Review study illustrating that those with professional degrees, such as physicians, have the highest rates of loneliness among all professions. ${ }^{17}$ Previous research in a sample of physicians in Kansas illustrated that the prevalence of loneliness was $43 \%$ among respondents. ${ }^{18}$ While loneliness has been linked to physician burnout, ${ }^{18-22}$ this has not been demonstrated in a national sample of practicing physicians.

Given the known individual and systematic impacts of physician psychological distress, in addition to the relationship between physician wellbeing and quality of care,$^{23}$ it is important to learn about emotional stress experienced by physicians. A greater understanding of the national experience of physician loneliness, burnout, and other forms of emotional distress would allow for a more informed and generalizable discussion about individual and organizational approaches to mitigate negative impacts. This study aimed to assess the prevalence of loneliness, burnout, and depressive symptoms from a national sample of family medicine physicians.

\section{Methods}

\section{Study Design and Participants}

The study was a cross-sectional survey of physicians who were members of the American Academy of Family Physicians (AAFP) and AAFP National Research Network (NRN) between December 7, 2019, and January 20, 2020. The study participants ( $\mathrm{n}=401$ ) completed an anonymous, 30-item survey that included questions regarding loneliness, burnout, symptoms of depression, fatigue, in addition to personal demographic information. The survey link was emailed to all members of the AAFP NRN and the AAFP Member Insight Exchange, a subset of
AAFP members who agree to be contacted for surveys. The AAFP Institutional Review Board gave this study exempt status on review.

Table 1 presents the demographic information of the respondents. The mean age of respondents was 50.2 years (standard deviation $[\mathrm{SD}]=11.1$ ). A slight majority were female $(53.1 \%)$, most were employed full-time (84.4\%), worked in urban areas (85.0\%), and were members of AAFP Member Insight Exchange (71.8\%). The mean years in clinical practice among the physicians was 18.9 years $(\mathrm{SD}=11.3)$.

\section{Study Instruments}

\section{Loneliness}

We assessed the physicians' level of loneliness using a 3-item University of California, Los Angeles (UCLA) Loneliness Scale, a validated shortened screening tool to measure loneliness. ${ }^{24,25}$ The questions are: How often do you feel that you lack companionship? How often do you feel left out? How often do you feel isolated from others? Participants recorded their responses on a 3-point Likert-like scale $(1=$ Hardly ever, $2=$ Sometimes, and $3=$ Often $)$. Scores for the 3 questions were summed, with a possible score ranging from 3 to 9 . As a standard practice, ${ }^{25,26}$ respondents who had a total score of 6 or above were considered "lonely."

\section{Burnout}

Assessment of burnout among the respondents used 2 single-item measures of overwhelming exhaustion and depersonalization adapted from the full Maslach Burnout Inventory (MBI-22), which has been validated. ${ }^{27}$ The overwhelming exhaustion item ("I feel burnout from my work") and depersonalization item ("I've become more callous toward people since I became a physician") have been shown to be useful screening questions for burnout. ${ }^{28-30}$ These 2 items have shown the highest factor loading ${ }^{27,31,32}$ and strong correlation ${ }^{28,33}$ with their respective emotional exhaustion and depersonalization domains in the MBI-22. ${ }^{28}$ The 2 single items have been used in previous studies to measure manifestations of burnout among physicians. , 34-36 $^{-3}$ The respondents recorded the degree to which each item applied to them on a 7-point Likert-like scale $(0=$ Never, $6=$ Every day $)$. The scores of each domain were grouped into low, moderate, and high burnout categories using established cutoffs. ${ }^{8,27,34,36}$ Higher scores are indicative of greater exhaustion 
Table 1. Respondents' Characteristics, $(n=401)$

\begin{tabular}{|c|c|c|c|}
\hline Characteristic & $\mathrm{N}(\%)^{*}$ & Characteristic & $\mathrm{N}(\%)$ \\
\hline Gender & & Primary employer & \\
\hline Male & $171(46.3)$ & Self-employed & $80(20.0)$ \\
\hline Female & $196(53.1)$ & Physician group & $71(19.2)$ \\
\hline Other & $2(0.6)$ & University owned clinic or hospital & $48(13.0)$ \\
\hline Missing & 33 & Private for-profit hospital or health system & $20(5.4)$ \\
\hline Age, years & & Private non-profit hospital or health system & $86(23.3)$ \\
\hline Mean $\pm \mathrm{SD}$ & $50.2 \pm 11.1$ & Managed care or insurance company & $10(2.7)$ \\
\hline Age group & & Federal, state, or local government, community board, etc. & $25(6.8)$ \\
\hline $25-34$ & $26(7.1)$ & Locum tenens group/staffing organization & $3(0.8)$ \\
\hline $35-44$ & $99(27.0)$ & Medical school & $10(2.7)$ \\
\hline $45-54$ & $111(30.3)$ & Other & $16(4.3)$ \\
\hline $55-64$ & $84(23.0)$ & Missing $^{\dagger}$ & 32 \\
\hline$\geq 65$ & $46(12.6)$ & Primary patient care location & \\
\hline Missing $^{\dagger}$ & 35 & Privately-owned medical practice & $171(46.5)$ \\
\hline Employment status & & Federally Qualified Community Health Center & $37(10.1)$ \\
\hline Full-time & $331(84.4)$ & Other clinic & $104(28.3)$ \\
\hline Part-time & $49(12.5)$ & Hospital (not emergency department) & $7(1.9)$ \\
\hline Fully retired & $8(2.0)$ & Hospital (emergency department) & $3(0.8)$ \\
\hline $\begin{array}{l}\text { Not in workforce for } \\
\text { other reasons }\end{array}$ & $4(1.0)$ & Urgent care facility & $12(3.3)$ \\
\hline Missing $^{\dagger}$ & 9 & $\begin{array}{l}\text { Institutional residential facility (student health, prisons, } \\
\text { nursing homes) }\end{array}$ & $12(3.3)$ \\
\hline Specialty & & Do not see patients in primary setting & $13(3.5)$ \\
\hline Family medicine & $359(97.6)$ & Other & $9(2.4)$ \\
\hline $\begin{array}{l}\text { General internal } \\
\text { medicine }\end{array}$ & $2(0.5)$ & Missing $^{\dagger}$ & 33 \\
\hline Emergency medicine & $1(0.3)$ & Percentage of work time in clinical practice & \\
\hline Pediatrics & - & $<50 \%$ & $94(24.3)$ \\
\hline Obstetrics/gynecology & - & $50 \%$ & $13(3.4)$ \\
\hline Other & $6(1.6)$ & $>50 \%$ & $280(72.4)$ \\
\hline Missing $^{\dagger}$ & 33 & Missing & 14 \\
\hline
\end{tabular}

${ }^{*}$ Results presented as number $(\mathrm{N})$ and percentage (\%) unless denoted otherwise.

${ }^{\dagger}$ The number of physicians who completed the survey but did not provide an answer to this specific question. Missing responses were excluded from the total before percentages were calculated.

SD, standard deviation.

and depersonalization, and greater burnout. Consistent with convention, ${ }^{8,34,36}$ we considered respondents who scored high (score of greater than 3) on exhaustion and/or depersonalization domains as having at least 1 manifestation of professional burnout.

\section{Symptoms of Depression and Fatigue}

We screened for symptoms of depression using a 2item Primary Care Evaluation of Mental Disorders Patient Health depression-screening questionnaire (PHQ-2). The questions asked the participants about their feelings of being down, depressed, or hopeless and if they have been bothered by little interest or pleasure in usual activities during the past month.
The 2-question screener has a reported $96 \%$ sensitivity and $57 \%$ specificity for depression. ${ }^{37,38}$ The PHQ-2 is an accurate depression screening in adults and used in previous studies to screen for symptoms of depression among physicians. ${ }^{18,30,39-41}$

We measured the physicians' levels of fatigue during the past week using a standardized linear analog scale $(0=a s$ bad as it can be, to $10=$ as good as it can be $)$ similar to what is described by West and colleagues. ${ }^{42}$ Respondents who scored 5 or less on the scale were considered to have higher levels of fatigue. ${ }^{30,34,39}$

\section{Statistical Analyses}

Standard descriptive statistics were used to create a demographic profile and describe the prevalence of 
Table 1. Respondents' Characteristics, $(n=401)$ Continued

\begin{tabular}{|c|c|c|c|}
\hline Characteristic & $\mathrm{N}(\%)^{*}$ & Characteristic & $\mathrm{N}(\%)$ \\
\hline Years in clinical practice & & Percentage of work time in administration/managerial & \\
\hline Mean \pm SD & $18.9 \pm 11.3$ & $<50 \%$ & $344(88.9)$ \\
\hline Minimum & $<1(0.8)$ & $50 \%$ & $10(2.6)$ \\
\hline Maximum & $51(0.3)$ & $>50 \%$ & $33(8.5)$ \\
\hline Missing $^{\dagger}$ & 33 & Missing & 14 \\
\hline Practice location & & Percentage of work time in research & \\
\hline Urban & $307(85.0)$ & $<50 \%$ & $386(96.3)$ \\
\hline Large rural & $26(7.2)$ & $50 \%$ & - \\
\hline Small rural & $21(5.8)$ & $>50 \%$ & $1(0.3)$ \\
\hline Isolated & $7(1.9)$ & Missing $^{\dagger}$ & 14 \\
\hline Missing $^{\dagger}$ & 40 & Percentage of work time in teaching & \\
\hline Membership & & $<50 \%$ & $375(96.9)$ \\
\hline AAFP Member Insight Exchange & $288(71.8)$ & $50 \%$ & $4(1.0)$ \\
\hline \multirow[t]{2}{*}{ AAFP NRN Member } & $113(28.2)$ & $>50 \%$ & $8(2.1)$ \\
\hline & & Missing $^{\dagger}$ & 14 \\
\hline
\end{tabular}

AAFP, American Academy of Family Physicians; NRN, National Research Network.

${ }^{*}$ Results presented as number $(\mathrm{N})$ and percentage (\%) unless denoted otherwise.

${ }^{\dagger}$ The number of physicians who completed the survey but did not provide an answer to this specific question. Missing responses were excluded from the total before percentages were calculated.

loneliness, burnout, depression, and fatigue among the respondents. Mann-Whitney U test/independent samples t-test and/or Kruskal-Wallis test/1-way ANOVA (for continuous variables), and Likelihood Ratio Chi-square (for categorical variables) were used to evaluate the association between variables. Generalized linear mixed models were used to calculate associations between the loneliness classification modeled as a binary outcome against a single fixed effect for independent variables (age, gender, employment status [whether a participant is employed part-time, full-time, fully retired, or not in the workforce for other reasons], practice location, membership [AAFP Member Insight Exchange and AAFP NRN], depression, emotional exhaustion, depersonalization, and fatigue).

Adjusted odds ratios were estimated by modeling all significant independent variables against the loneliness classification, controlling for respondent age, gender, employment status, practice location, and membership. Adequate power $(>0.85)$ to detect significant relationships among the variables with 2 degrees of freedom, $P<.05$, and 0.21 effect size required a sample size of 350 respondents. ${ }^{43,44}$ All analyses were 2 -sided with $\alpha$ of 0.05 . The IBM SPSS (Statistical Package for the Social Sciences; Armonk, NY), version 26 was used for these analyses.

\section{Results}

The response rates were $16.3 \%$ (401 of 2456) for all the physicians, $7.0 \%$ (113 of 1606) for the AAFP NRN member physicians, and $33.9 \%$ (288 of 850 ) for the AAFP member insight physicians. There was a $4.5 \%$ margin of error at a $95 \%$ confidence level between the study sample and the overall physicians who were members of the AAFP population, demonstrating that our sample generally represented the overall AAFP population. ${ }^{45}$ Table 2 summarizes the prevalence of loneliness, burnout, depression, and fatigue. Throughout the document, we used the term depression to indicate a positive screen for depressive symptoms.

\section{Loneliness}

The overall prevalence of loneliness was $44.9 \%$ (165 of 367). The mean score and standard deviation on the 3-item UCLA Loneliness Scale was $5.3 \pm 1.9$, with more than half of the physicians sometimes or often feeling a lack of companionship, left out, or isolated from others (Figure 1). The mean loneliness score varied by gender, with female respondents scoring higher $(5.6 \pm 1.9)$ than male respondents $(5.1 \pm 1.9, P=.012$; Table 2$)$. As Table 3 shows, loneliness was significantly associated with years in clinical practice. Physicians with more years 
Table 2. Loneliness, Burnout, Depression, and Fatigue Among Physicians Who Participated in the Study, $(\mathrm{n}=$ 401)

\begin{tabular}{|c|c|c|c|c|}
\hline Characteristic & All Participants $(\mathrm{n}=401)$ & Female $(n=196)$ & Male $(\mathrm{n}=171)$ & $P$ value \\
\hline & $\mathrm{N}(\%)^{*}$ & $\mathrm{~N}(\%)^{*}$ & $\mathrm{~N}(\%)^{*}$ & \\
\hline \multicolumn{5}{|l|}{ Loneliness } \\
\hline Mean \pm SD & $5.3 \pm 1.9$ & $5.6 \pm 1.9$ & $5.1 \pm 1.9$ & .012 \\
\hline \multicolumn{5}{|l|}{ Prevalence of loneliness } \\
\hline Screened as lonely & $165(44.9)$ & $95(48.7)$ & $68(40.5)$ & .091 \\
\hline Screened as not lonely & $202(55.0)$ & $100(51.3)$ & $100(59.5)$ & .211 \\
\hline Missing $^{\dagger}$ & 34 & 1 & 3 & \\
\hline \multicolumn{5}{|l|}{ Burnout Index ${ }^{\ddagger}$} \\
\hline Emotional exhaustion: high score ${ }^{f}$ & $135(33.7)$ & $84(43.1)$ & $51(30.4)$ & .008 \\
\hline Depersonalization: high score ${ }^{\mathrm{f}}$ & $138(34.4)$ & $84(43.1)$ & $54(32.1)$ & .019 \\
\hline Burned out & $181(45.1)$ & $111(56.9)$ & $70(41.7)$ & .004 \\
\hline \multicolumn{5}{|l|}{ Depression } \\
\hline Screened positive for depression & $163(44.3)$ & $100(51.0)$ & $63(36.8)$ & .004 \\
\hline Missing $^{\dagger}$ & 33 & - & - & \\
\hline \multicolumn{5}{|l|}{ Fatigue $^{\S}$} \\
\hline Mean \pm SD & $5.8 \pm 2.4$ & $5.3 \pm 2.4$ & $6.3 \pm 2.3$ & $<.001$ \\
\hline \multicolumn{5}{|l|}{ Level of fatigue in the past week } \\
\hline Low & $182(53.1)$ & $82(44.8)$ & $99(63.1)$ & $<.001$ \\
\hline High & $161(46.9)$ & $101(55.2)$ & $58(36.9)$ & $<.001$ \\
\hline Missing $^{\dagger}$ & 58 & 13 & 14 & \\
\hline
\end{tabular}

${ }^{*}$ Results presented as number $(\mathrm{N})$ and percentage (\%) unless denoted otherwise.

${ }^{\dagger}$ The number of physicians who completed the survey but did not provide an answer to this specific question. Missing responses were excluded from the total before percentages were calculated.

${ }^{\ddagger}$ We assessed burnout using 2 single-item measures for emotional exhaustion and depersonalization adapted from the full Maslach Burnout Inventory.

${ }^{\mathrm{f}}$ High score on Emotional Exhaustion and/or Depersonalization subscale of the Maslach Burnout Inventory.

${ }^{\S}$ Scores ranged from 0 to 10 , with a low mean fatigue score suggesting higher or worsened fatigue.

$\mathrm{SD}$, standard deviation.

in practice had lower levels of loneliness $(P=.019)$. There was not a significant association between agegroup, gender, employment status, practice location, or membership and loneliness score.

\section{Burnout}

In aggregate, $45.1 \%$ of the physicians reported at least 1 manifestation of burnout. The manifestation of burnout varied by sex, with $56.9 \%$ of female respondents compared with $41.7 \%$ of male respondents reporting manifestations of burnout $(P=.004)$.

\section{Depression and Fatigue}

Overall, $44.3 \%$ (163 of 368 ) of the respondents screened positive for depression. Depression by sex, with $51.0 \%$ (100 of 196) of female respondents versus $36.8 \%$ (63 of 171) of male respondents screening positive $(P=.004)$. Nearly $46.9 \%$ (161 of 343 ) of the respondents reported excessive fatigue during the prior week. The level of fatigue varied by sex as $55.2 \%$ (101 of 183 ) of the female respondents compared with $36.9 \%$ (58 of 157 ) of the male respondents reported experiencing excessive fatigue during the prior week $(P<.001)$.

\section{Loneliness and Other Types of Emotional Distress}

As shown in Table 4, respondents with higher loneliness scores reported at least 1 manifestation of burnout $(69.1 \%$ vs $27.4 \%, P<.01)$, were more likely to screen positive for depression $(66.0 \%$ vs $27.6 \%, P<.01)$ and experienced a higher degree of fatigue $(59.5 \%$ vs $32.4 \%, P<.01)$.

Findings of the mixed model analyses indicated that there was a significant positive association between loneliness and depression (odds ratio $[\mathrm{OR}]=5.08 ; 95 \%$ confidence interval $[\mathrm{CI}], 4.64-$ 7.94; $P<.001$; Table 3). This association remained significant after adjusting for the respondent age, gender, employment status, practice location, and 
Figure 1. Percentage of responses to the 3-item University of California, Los Angeles (UCLA) Loneliness Scale

$\square$ Hardly ever $\square$ Sometimes $\square$ Often

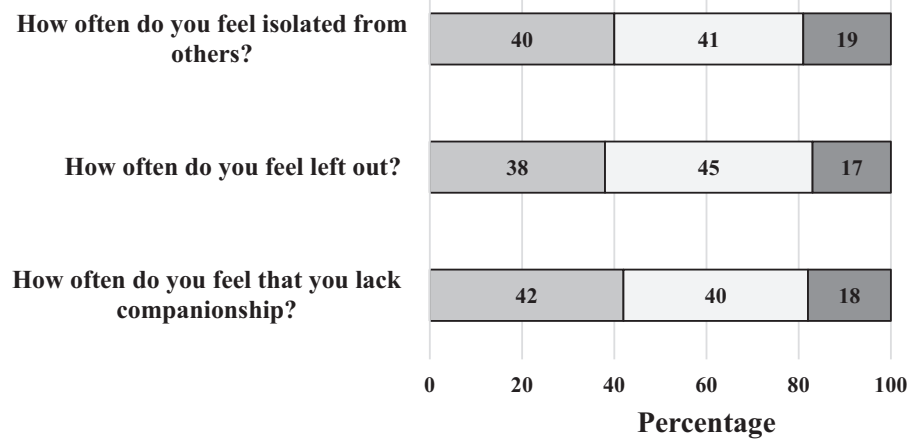

membership (adjusted OR $[\mathrm{aOR}]=2.24 ; 95 \% \mathrm{CI}$, $0.97-5.19 ; P<.001)$. In addition, respondents who reported a high level of overwhelming exhaustion experienced a higher level of loneliness $(\mathrm{OR}=7.19$; 95\% CI, 4.03-12.02; $P<.001$; Table 3). This association remained significant after adjusting for all respondent characteristics $(\mathrm{aOR}=1.26 ; 95 \% \mathrm{CI}$, $0.99-1.61 ; P<.01)$.

A higher level of loneliness associated positively with manifestations of burnout $(\mathrm{OR}=4.61 ; 95 \%$ CI, 2.96-7.19; $P<.001$; Table 3), high score of depersonalization $(\mathrm{OR}=4.76$; 95\% CI, 2.58-8.77; $P<.001$; Table 3 ), and a high degree of fatigue $(\mathrm{OR}=4.63 ; 95 \%$ CI, 1.91-7.63; $P<.001)$. These associations were not significant after adjusting for the respondent's age, gender, employment status, practice location, and membership.

\section{Discussion}

While previous research has investigated physician burnout and physician depression, this cross-sectional survey is one of the first studies to also look at physician loneliness and its associations with other forms of emotional distress. In this study, $44.9 \%$ of a national sample of family medicine physicians identified as lonely. The prevalence of depression and burnout was $44.3 \%$ and $45.1 \%$, respectively. Physicians who experienced a greater feeling of loneliness were more likely to report at least 1 manifestation of burnout, screen positive for depression, and experience a higher degree of fatigue than those who experienced a lesser feeling of loneliness. The associations between loneliness and depression in addition to loneliness and exhaustion remained significant after adjusting for the respond-

ents' age, gender, employment status, practice location, and membership.

The high prevalence of loneliness in this national sample of family medicine physicians and the association with both depression and burnout mirrors results from a prior study assessing Kansas family physicians. ${ }^{18}$ In addition, our high depression and burnout prevalence rates are in line with findings of previous studies. ${ }^{18,34,39,46}$ Family medicine physicians typically spend their days interacting with other health care professionals, staff, and patients; however, our results demonstrate that loneliness and emotional distress can occur even in clinical environments. Family medicine physicians often have to cope with substantial administrative and regulatory burdens. ${ }^{47}$ Such tasks may be adversely affecting their ability to interact with colleagues in meaningful ways and could potentially be leading to loneliness. ${ }^{19,48}$ Instead of focusing on developing meaningful clinical relationships with patients, physicians may be becoming more focused on "clicking the boxes," and documentation due to increased government regulation, malpractice suits, and health system demands. Further exploration of the factors influencing the loneliness and emotional distress among family medicine physicians may reveal additional or different contributing factors and thus inform interventions. Although we captured perceived social isolation in this study, other authors have suggested that there are also structural and professional components to isolation, illustrating the potential multi-factorial effect of the workplace environment. ${ }^{19,49}$

Loneliness and depression are known to be associated in the general population, ${ }^{50}$ though loneliness and burnout are correlated in certain 
Table 3. Odds Ratios for Independent Variables and Loneliness, $(\mathrm{n}=401)$

\begin{tabular}{|c|c|c|}
\hline Variable & Odds Ratio (95\% CI) & $P$ value \\
\hline \multicolumn{3}{|l|}{ Age, years } \\
\hline $25-34$ & $1.86(0.87-3.95)$ & .534 \\
\hline $35-44$ & $1.30(0.63-2.70)$ & .103 \\
\hline $45-54$ & $2.35(1.13-4.93)$ & .386 \\
\hline $55-64$ & $1.33(0.48-3.66)$ & .088 \\
\hline$>64$ & Reference & - \\
\hline \multicolumn{3}{|l|}{ Gender } \\
\hline Female & $1.40(0.92-2.12)$ & .999 \\
\hline Male & Reference & - \\
\hline \multicolumn{3}{|l|}{ Employment status } \\
\hline Part-time & $1.28(0.69-2.38)$ & .152 \\
\hline Full-time & Reference & \\
\hline Years in clinical practice (for additional year in practice) & $1.02(1.00-1.04)$ & .019 \\
\hline \multicolumn{3}{|l|}{ Practice location } \\
\hline Urban & $0.57(0.10-3.38)$ & .861 \\
\hline Large rural & $0.97(0.18-5.29)$ & .979 \\
\hline Small rural & $1.13(0.25-5.13)$ & .487 \\
\hline Isolated & Reference & \\
\hline \multicolumn{3}{|l|}{ Membership } \\
\hline AAFP Member Insight Exchange & $1.11(0.69-1.79)$ & .662 \\
\hline AAFP NRN member & Reference & \\
\hline \multicolumn{3}{|l|}{ Depression } \\
\hline Screened positive & $5.08(4.64-7.94)$ & $<.001$ \\
\hline Screen negative & Reference & - \\
\hline \multicolumn{3}{|l|}{ Manifestations of burnout } \\
\hline Burned out & $4.61(2.96-7.19)$ & $<.001$ \\
\hline Not burnout & Reference & - \\
\hline \multicolumn{3}{|l|}{ Emotional exhaustion } \\
\hline High score & $7.19(4.03-12.02)$ & $<.001$ \\
\hline Moderate score & $2.85(1.59-5.10)$ & $<.001$ \\
\hline Low score & Reference & - \\
\hline \multicolumn{3}{|l|}{ Depersonalization } \\
\hline High score & $4.76(2.58-8.77)$ & $<0.001$ \\
\hline Moderate score & $1.45(0.79-2.65)$ & .251 \\
\hline Low score & Reference & - \\
\hline \multicolumn{3}{|l|}{ Level of fatigue } \\
\hline High degree & $4.63(1.91-7.63)$ & $<0.001$ \\
\hline Low degree & Reference & - \\
\hline
\end{tabular}

AAFP, American Academy of Family Physicians; CI, confidence interval; NRN, National Research Network.

populations, such as medical residents. ${ }^{21,22}$ To our knowledge, this is the first study illustrating a relationship of loneliness to both depression and burnout in a national sample of physicians. Although loneliness, burnout (overwhelming exhaustion), and depression are overlapping constructs of helplessness, these states of emotional distress seem to be distinct phenomena, ${ }^{51}$ where loneliness is due to unmet social needs, burnout is a negative work- related state of mind, and depression is a sadness that may impact all areas of someone's life. There is a paucity of research on the temporal relation between loneliness and burnout, although other authors have suggested that loneliness may increase vulnerability to environmental stressors leading to burnout and that social networks and relationships may help mitigate the negative impacts of burnout. ${ }^{21,22}$ In support of this, one study illustrated 
Table 4. Relationship of Burnout, Depression, and Fatigue with Loneliness Among the Physicians

\begin{tabular}{|c|c|c|c|c|c|}
\hline \multirow[b]{2}{*}{ Variable } & \multicolumn{2}{|c|}{ Loneliness } & \multirow[b]{2}{*}{$\chi^{2}$} & \multirow[b]{2}{*}{$P$ value } & \multirow[b]{2}{*}{ Phi } \\
\hline & $\begin{array}{l}\text { Lonely } \\
\text { N (\%) }\end{array}$ & $\begin{array}{l}\text { Nonlonely } \\
\text { N (\%) }\end{array}$ & & & \\
\hline Manifestation of burnout & & & 47.95 & $<.001$ & 0.357 \\
\hline Present & $114(69.1)$ & $67(37.0)$ & & & \\
\hline Not present & $51(27.4)$ & $135(72.6)$ & & & \\
\hline Total & $165(45.0)$ & $202(55.0)$ & & & \\
\hline Depression & & & 55.10 & $<.001$ & 0.384 \\
\hline Screened positive for depression & $107(66.0)$ & $55(34.0)$ & & & \\
\hline Screened negative for depression & $56(27.6)$ & $147(72.4)$ & & & \\
\hline Total & $163(44.7)$ & $202(55.3)$ & & & \\
\hline Level of fatigue & & & 25.32 & $<.001$ & 0.271 \\
\hline High degree & $94(59.5)$ & $64(40.5)$ & & & \\
\hline Low degree & $59(32.4)$ & $123(67.6)$ & & & \\
\hline Total & $153(45.0)$ & $187(55.0)$ & & & \\
\hline
\end{tabular}

that lower levels of social capital were associated with decreased academic performance in minority medical students, ${ }^{52}$ highlighting the importance of social ties in a health care context.

Physician loneliness was not associated with practice location or employment status. Our results corroborate other studies that have not documented a significant difference in loneliness between respondents in rural and urban settings. ${ }^{53-55}$ Generalizability of our findings may be somewhat limited, as $85 \%$ of the respondents practiced in urban settings. While social and professional isolation may be more common in rural practice settings, structural isolation can occur in any practice setting. ${ }^{49}$

While age was not associated with loneliness scores, physicians with additional years of practice were less likely to consider themselves lonely. Previous literature on other forms of physician emotional distress suggests that burnout and depression begin early in the medical career and increase throughout training; ${ }^{34,56}$ our results illustrate that this may also be the case for loneliness. The reasons for this are not clear, but we hypothesize that physicians who are more established in their clinical settings have had more time to develop meaningful relationships within physician groups and in their community. It may also be that younger physicians, accustomed to working in groups during the training, are assigned into practice settings where there are fewer professional interactions, which in turn contributes to isolation. $^{57}$ Notably, this trend of younger persons suffering more loneliness is also illustrated in the general population, which suggests the potential contribution of external factors such as increased societal fragmentation, concerns with self-identity, and significant life transitions. ${ }^{1,58,59}$

Overall, our data highlight the urgent need to examine the underlying causes and components of physician loneliness to inform interventions that elevate physician wellbeing. Although there is significant attention on physician burnout, our results illustrate that the current narrative on physician unhappiness must expand to include loneliness. ${ }^{60}$ As other authors have noted, there are likely 3 types of isolation contributing to physician distress: professional, structural, and social isolation. ${ }^{49}$ The increasing fragmentation of medicine and "disconnected workplace" for family medicine physicians may result in structural and professional isolation, while difficulty making and sustaining meaningful relationships with patients and colleagues may contribute to social isolation. ${ }^{19,48}$ These multi-level factors must all be considered in future organizational and individual strategies to reduce loneliness among physicians. In addition, our results endorse the need to better understand loneliness in younger family medicine physicians, potentially involving solutions such as curricular changes that mitigate emotional distress in training physicians. ${ }^{61}$

\section{Study Limitations}

There were some limitations to the study given the cross-sectional nature and low response rate. 
Response rates were typical of surveys $8,9,18,39,46$ but were lower in the AAFP NRN members. The lower response rate for AAFP NRN members may have been because compensation was not provided for this survey; when compensated, the response rates tend to be in the more typical range for AAFP NRN members. ${ }^{62,63}$ The low participation rate likely contributes to some non-responder bias that could affect the interpretation of the results. Emotionally distressed physicians may be less motivated to respond to the survey, or more likely to participate because the topic may be relevant to them. Given the anonymous nature of the survey that was emailed to members of the AAFP NRN and AAFP Member Insight Exchange, which are not necessarily mutually exclusive groups, we are unable to account for any double-counting of responses. In addition, while we found correlations among loneliness, depression, and physician burnout, we are unable to determine which of these factors if any, leads to the other two. However, prior literature has shown that loneliness predicts depressive symptomatology, even after controlling for objective social isolation, stress, and social support. ${ }^{50}$ While this study was unable to ascertain the reasons for physician loneliness, further research should explore these root causes, which could help drive practice changes and inform interventions focused on physician wellbeing. In addition, future research should focus on longitudinal monitoring of younger physicians to determine which factor represents a tipping point for the others or if they co-occur.

\section{Conclusion}

The prevalence of loneliness in practicing family medicine physicians is high and is significantly associated with burnout and depression. Our findings contribute to the growing body of evidence demonstrating the disproportionate amount of emotional distress experienced by physicians. In response, health care systems, employers, and payers need to prioritize understanding and addressing the factors relating to physician wellbeing. Future research ought to study the temporal relationship between loneliness, burnout, depression, and the factors related to the manifestation of these conditions to inform effective interventions.

\footnotetext{
To see this article online, please go to: http://jabfm.org/content/ 34/3/531.full.
}

\section{References}

1. Heinrich LM, Gullone E. The clinical significance of loneliness: a literature review. Clin Psychol Rev 2006;26:695-718.

2. Holt-Lunstad J, Smith TB. Loneliness and social isolation as risk factors for CVD: implications for evidence-based patient care and scientific inquiry. Heart 2016;102:987-9.

3. Holt-Lunstad J, Smith TB, Baker M, Harris T, Stephenson D. Loneliness and social isolation as risk factors for mortality: a meta-analytic review. Perspect Psychol Sci 2015;10:227-37.

4. Petitte T, Mallow J, Barnes E, Petrone A, Barr T, Theeke L. A systematic review of loneliness and common chronic physical conditions in adults. Open Psychol J 2015;8:113-32.

5. Wilson C, Moulton B. Loneliness among older adults: a national survey of adults $45+$. Knowledge Networks and Insight Policy Research. 2010. Available from: https://www.aarp.org/content/dam/ aarp/research/surveys_statistics/general/2012/loneliness2010.doi.10.26419\%252Fres.00064.001.pdf. Accessed June 25, 2020.

6. Holt-Lunstad J, Robles TF, Sbarra DA. Advancing social connection as a public health priority in the United States. Am Psychol 2017;72:517-30.

7. Reith TP. Burnout in United States healthcare professionals: a narrative review. Cureus 2018;10:e3681.

8. Shanafelt TD, Boone S, Tan L, et al. Burnout and satisfaction with work-life balance among US physicians relative to the general US population. Arch Intern Med 2012;172:1377-85.

9. Shanafelt TD, Hasan O, Dyrbye LN, et al. Changes in burnout and satisfaction with work-life balance in physicians and the general US working population between 2011 and 2014. Mayo Clin Proc 2015;90:1600-13.

10. Welp A, Meier LL, Manser T. Emotional exhaustion and workload predict clinician-rated and objective patient safety. Front Psychol 2014;5:1573.

11. Shanafelt TD, Balch CM, Bechamps G, et al. Burnout and medical errors among American surgeons. Ann Surg 2010;251:995-1000.

12. Dyrbye LN, Massie FS, Jr., Eacker A, et al. Relationship between burnout and professional conduct and attitudes among US medical students. JAMA 2010;304:1173-80.

13. Halbesleben JRB, Rathert C. Linking physician burnout and patient outcomes: Exploring the dyadic relationship between physicians and patients. Health Care Manage Rev 2008;33:29-39.

14. Anagnostopoulos F, Liolios E, Persefonis G, Slater J, Kafetsios K, Niakas D. Physician burnout and patient satisfaction with consultation in primary health care settings: evidence of relationships from a one-with-many design. J Clin Psychol Med Settings 2012;19:401-10. 
15. Willard-Grace R, Knox M, Huang B, Hammer H, Kivlahan C, Grumbach K. Burnout and health care workforce turnover. Ann Fam Med 2019; 17:36-41.

16. Noseworthy J, Madara J, Cosgrove D, et al. Physician burnout is a public health crisis: a message to our fellow health care CEOs. Health Affairs Blog 2017. Available from: https://www.healthaffairs.org/ do/10.1377/hblog20170328.059397/full/. Accessed June 25, 2020.

17. Achor S, Kellerman GR, Reece A, Robichauz A. America's loneliness workers, accoring to research. Available from: https://hbr.org/2018/03/americasloneliest-workers-according-to-research. Published 2018. Accessed June 25, 2020.

18. Ofei-Dodoo S, Ebberwein C, Kellerman R. Assessing loneliness and other types of emotional distress among practicing physicians. Kans J Med 2020;13:1-5.

19. Frey JJ., 3rd. Professional loneliness and the loss of the doctors' dining room. Ann Fam Med 2018; 16:461-3.

20. Seppala E, King M. Burnout at work isn't just about exhaustion. it's also about loneliness. Harvard Business Review. Available from: https://hbr.org/ 2017/06/burnout-at-work-isnt-just-about-exhaustionits-also-about-loneliness. Published 2017. Accessed June 25, 2020.

21. Rogers E, Polonijo AN, Carpiano RM. Getting by with a little help from friends and colleagues: testing how residents' social support networks affect loneliness and burnout. Can Fam Physician 2016; 62:e677-83.

22. Shapiro J, Zhang B, Warm EJ. Residency as a social network: burnout, loneliness, and social network centrality. J Grad Med Educ 2015;7:617-23.

23. Bodenheimer T, Sinsky C. From triple to quadruple aim: care of the patient requires care of the provider. Ann Fam Med 2014;12:573-6.

24. Hughes ME, Waite LJ, Hawkley LC, Cacioppo JT. A short scale for measuring loneliness in large surveys: results from two population-based studies. Res Aging 2004;26:655-72.

25. Steptoe A, Shankar A, Demakakos P, Wardle J. Social isolation, loneliness, and all-cause mortality in older men and women. PNAS 2013;110:5797-801.

26. Russell D, Peplau LA, Cutrona CE. The revised UCLA Loneliness Scale: concurrent and discriminant validity evidence. J Pers Soc Psychol 1980; 39:472-80.

27. Maslach C, Jackson SE, Leiter MP. Maslach Burnout Inventory Manual. 3rd ed. Palo Alto, CA: Consulting Psychologists Press; 1996.

28. West CP, Dyrbye LN, Sloan JA, Shanafelt TD. Single item measures of emotional exhaustion and depersonalization are useful for assessing burnout in medical professionals. J Gen Intern Med 2009; 24:1318-21.
29. Rafferty JP, Lemkau JP, Purdy RR, Rudisill JR. Validity of the Maslach Burnout Inventory for family practice physicians. J Clin Psychol 1986;42:488-92.

30. Ofei-Dodoo S, Moser SE, Kellerman R, Wipperman J, Paolo A. Burnout and other types of emotional distress among medical students. Med Sci Educator 2019;29:1061-69.

31. Kanste O, Miettunen J, Kyngas H. Factor structure of the Maslach Burnout Inventory among Finnish nursing staff. Nurs Health Sci 2006;8:201-7.

32. Vanheule S, Rosseel Y, Vlerick P. The factorial validity and measurement invariance of the Maslach Burnout Inventory for human services. Stress \& Health 2007;23:87-91.

33. West CP, Dyrbye LN, Satele DV, Slon JA, Shanafelt TD. Concurrent validity of single-item measures of emotional exhaustion and depersonalization in burnout assessment. J Gen Intern Med 2012;27:1445-52.

34. Dyrbye LN, West CP, Satele D, et al. Burnout among U.S. medical students, residents, and early career physicians relative to the general U.S. population. Acad Med 2014;89:443-51.

35. Dyrbye LN, Thomas MR, Massie FS, et al. Burnout and suicidal ideation among U.S. medical students. Ann Intern Med 2008;149:334-41.

36. Maslach C, Schaufeli WB, Leiter MP. Job burnout. Annu Rev Psychol 2001;52:397-422.

37. Whooley MA, Avins AL, Miranda J, Browner WS. Case-finding instruments for depression. Two questions are as good as many. J Gen Intern Med 1997;12:439-45.

38. Spitzer RL, Williams JB, Kroenke K, et al. Utility of a new procedure for diagnosing mental disorders in primary care. The PRIME-MD 1000 study. JAMA 1994;272:1749-56.

39. Ofei-Dodoo S, Kellerman R, Gilchrist K, Casey EM. Burnout and quality of life among active member physicians of the Medical Society of Sedgwick County. Kans J Med 2019;12:33-9.

40. Gilbody S, House AO, Sheldon TA. Screening and case-finding instruments for depression. Cochrane Database Syst Rev 2005;CD002792.

41. Arroll B, Khin N, Kerse N. Screening for depression in primary care with two verbally asked questions: cross-sectional study. BMJ 2003;327:1144-6.

42. West CP, Tan AD, Habermann TM, Sloan JA, Shanafelt TD. Association of resident fatigue and distress with perceived medical errors. JAMA 2009; 302:1294-300.

43. Statistics Kingdom. Chi-square statistical power calculator. Available from: http://www.statskingdom. com/34test_power_chi2.html. Accessed July 20, 2020 .

44. Kim HY. Statistical notes for clinical researchers: Chi-squared test and Fisher's exact test. Restor Dent Endod 2017;42:152-5. 
45. Data Star, Inc. What every researcher should know about statistical significance. 2008. Available from: http://www.surveystar.com/startips/oct2008.pdf. Accessed December 28, 2020.

46. Shanafelt TD, West CP, Sinsky C, et al. Changes in burnout and satisfaction with work-life integration in physicians and the general us working population between 2011 and 2017. Mayo Clin Proc 2019;94:1681-94.

47. Ofei-Dodoo S, Callaway P, Engels K. Prevalence and etiology of burnout in a community-based graduate medical education system: a mixed-methods study. Fam Med 2019;51:766-71.

48. Daaleman TP. The long loneliness of primary care. Ann Fam Med 2018;16:388-9.

49. Barnett S, Jones SC, Bennett S, Iverson D, Bonney A. General practice training and virtual communities of practice - a review of the literature. BMC Fam Pract 2012;13:87.

50. Cacioppo JT, Hawkley LC, Thisted RA. Perceived social isolation makes me sad: 5-year cross-lagged analyses of loneliness and depressive symptomatology in the Chicago Health, Aging, and Social Relations Study. Psychol Aging 2010;25:453-63.

51. Wurm W, Vogel K, Holl A, et al. Depression-burnout overlap in physicians. PLoS One 2016;11:e0149913.

52. Vaughan S, Sanders T, Crossley N, O’Neill P, Wass V. Bridging the gap: the roles of social capital and ethnicity in medical student achievement. Med Educ 2015;49:114-23.

53. Mullen RA, Tong S, Sabo RT, et al. Loneliness in primary care patients: a prevalence study. Ann Fam Med 2019;17:108-15.

54. Menec VH, Newall NE, Mackenzie CS, Shooshtari S, Nowicki S. Examining social isolation and loneliness in combination in relation to social support and psychological distress using Canadian Longitudinal Study of Aging (CLSA) data. PLoS One 2020;15:e0230673.

55. Victor CR, Pikhartova J. Lonely places or lonely people? Investigating the relationship between loneliness and place of residence. BMC Public Health 2020;20:778.

56. Kalmoe MC, Chapman MB, Gold JA, Giedinghagen AM. Physician suicide: a call to action. Mo Med 2019;116:211-6.

57. Larkins SL, Spillman M, Parison J, Hays RB, Vanlint J, Veitch C. Isolation, flexibility and change in vocational training for general practice: personal and educational problems experienced by general practice registrars in Australia. Fam Pract 2004; 21:559-66.

58. Cigna CUS. loneliness index: survey of 20,000 Americans examining behaviors driving loneliness in the United States. Available from: https://www. multivu.com/players/English/8294451-cigna-uslonelinesssurvey/. Published May 1, 2018. Accessed January 9, 2021.

59. Perlman D, Landolt MA. Examination of loneliness in children- adolescents and in adults: two solitudes or a unified enterprise? In: Rotenberg KJ, Hymel S, eds. Loneliness in Childhood and Adolescence. Cambridge, England: Cambridge University Press; 1999: 325-47.

60. West CP, Dyrbye LN, Erwin PJ, Shanafelt TD. Interventions to prevent and reduce physician burnout: a systematic review and meta-analysis. Lancet 2016;388:2272-81.

61. Katzman J, Geppert C, Kilpatrick J, Graeber D, Arenella PB. The loneliness curriculum of psychiatric training. Acad Psychiatry 2016;40:111-6.

62. Bullard E. Measuring physicians' opinions of CER to strengthen its role in patient-centered care. Report to American College of Physicians. Available from: https://www.aafp.org/dam/AAFP/ documents/patient_care/nrn/manning-bullard-cer2015.pdf. Published September 8, 2015. Accessed September 10, 2020.

63. Ahlers-Schmidt CR, Chesser A, Hart T, et al. Assessing physician response rate using a mixedmode survey. Kans J Med 2010;3:1-6. 